\title{
Challenges Faced by Dental Patients Undergoing Dental Restoration in the Less Developed Countries
}

\author{
Kingsley Akarowhe ${ }^{1 *}$ \\ Department of Educational Foundations, University of Uyo, Nigeria
}

Received: February 02, 2018; Published: February 20, 2018

*Corresponding author: Kingsley Akarowhe, Department of Educational Foundations, University of Uyo, Faculty of Education, Nigeria, Tel: +234-08137640978; Email: kingsmith1172@gmail.com

\begin{abstract}
Dental problem is a phenomenon of global concern. Hence the international communities such as the United Nations and respective government of different nations tend to give attention to dental issues in terms of assisting their health sector. Often than not, this has yielded little results, due to the fact that dental restoration process has not yielded the expected outcome as anticipated by dental patients. This tends to raise a pitfall for dental practitioners (dentist), due to challenges often faced by dental patients undergoing dental restoration in most dental hospitals and dental centres in the less developed countries. The light of the forgoing provided the fertile ground for the researcher to investigate the challenges faced by dental patients and proffer solution insight, in terms of way-forward to the challenges. Based on the findings, it was recommended among other that workshops, symposia, seminars and field trips should be organised for dentist and their assisting staffs regularly, which will help in upgrading their skills and competencies in other for them to surmount some of the challenges patients tends to face.

Keywords: Dental Restoration; Dental Patient; Challenges in dental restoration; Way-forward
\end{abstract}

\section{Concept of Dental Restoration}

Dental restoration can be defined as a time process of restoring originally malfunctioning or loss tooth due to decay by prescribed medication or replacement of damage tooth by surgical operation in fixing new ones by a professional dentist. It can simply also be seen as a process of restoring originally loss tooth. Dental restoration also called dental filling [1,2]. It is a treatment to restore the function, integrity and morphology of missing tooth structure resulting from caries or external trauma as well as to the replacement of such structure supported by dental implants [1,2]. Dental restoration encompasses all the activities engage in by dental patients and a dentist for the purpose of removing obstacles faced by patients in using their tooth and enhancing a proper functioning of their tooth.

Dental restoration can be classified into two broad types.

Namely: Direct restoration and indirect restoration.

\section{Direct Dental Restoration}

Direct dental restoration or simply direct restoration. It is a technique that involves placing a soft or malleable filling into the prepared tooth and building up the tooth [3]. The material is then set hard and the tooth is restored [3]. In direct dental restoration, the dentist takes proactive steps or measures in preparing the filling materials in terms of its suitability and appropriateness, in placing the filling material on the patient tooth.

\section{Indirect Dental Restoration}

Indirect dental restoration also called indirect restoration. As the name implies, it is initially carried outside the patient mouth and later fixed on the predestinated portion of the patient tooth. In other words, restoration is fabricated outside of the mouth using the dental impression of prepared tooth. The common indirect restoration includes inlays and on-lay, crowns, bridges and veneers [3]. The prepared tooth by the dental technician on the prescription/directives of the dentist is permanently attached on the patient tooth through dental clement.

\section{Meaning of Dental Patient}

A patient is a person that is having health challenges, and as a result he/she needs necessary attention from a doctor in other for such challenges to be resolve. Similarly, a patient is a person who is receiving medical care or who is cared for by a particular doctor or dentist when necessary [4]. Dental patients are people who have dental ailment and are on medical prescription or are currently undergoing surgical operation on the directives of a dentist. Additionally, they can be seen as individual who experience some form of abnormalities in using their tooth, 
which makes them to be under the care/attention of a dentist.

Dental patients can be grouped into two:

\section{Patients under Medication}

These are patients who on the prescription of a dentist are advice to take medicines for a specified time frame, in other for them to recover from their dental ailment. Similarly, they can be seen as patients proven by a dentist to respond to medicines for them to surmount their tooth related ailment they face. Medical drugs ranging from analgesics, anesthetics, antibiotics, antifungal, fluorides, antiseptics, benzodiazepines and saliva substitutes are often prescribed for patients under medication by the dentist.

\section{Patients under Surgical Operation}

These are patients whose dental conduction needs prior operation by a professional dentist either through removing the tooth and fixing new ones or filling up some decade parts of the tooth. In simple terms, they are patients who are prescribed for operation by a dentist due to the abnormalities experienced by them in using their tooth and are currently undergoing such operation.

Challenges faced by dental patients undergoing dental operation in the less developed countries are as follows

\section{Communication Lags}

In any field of human endeavor communication is a pivotal for attainment of a given set goals and objective. In dental practice communication play a crucial role of bridging the lags between patients and dentist, hence enhancing effective information channeling process for the purpose of solving the dental problem of the patients. In the less developed countries, this has not been the case, as dentist and patients tends to experience lags in their communication. In light of this [5] opined that staying in constant contact with patients is one of the greatest challenges facing modern dental environment. Often than not, this hinders the dental restoration process and subsequently, inducing patients to switch to dentist that would care for them more in the aspect of communication that is easy access to the dentist.

\section{High Cost of Treatment}

The goal of providing the best patient care possibly is getting to provide the best struggle to afford treatment [6]. Dental patients in the less developed countries tend to experience finance constraint due to the high cost associated in treatment of their dental problem. As dental restoration process is a time frame process, patients are expected to spend much money especially those under surgical operation, before finally recovering from their tooth ailment. This often makes them to overview the dental restoration process as highly cost effective. In light of this [7] submitted that when people are hit with high drug costs, they are more likely to take unhealthy measures such as skipping doctor appointments, tests, or procedures, or not filling their prescriptions or taking them as directed. Similarly, most of the medicines prescribed to patients by dentist are usually exorbitant given the economic condition in these less developed countries, thus most dental patients in the less developed countries tend to stop treatment of their dental ailment and hence hindering the dental restoration process due to high cost involved.

\section{Lack of Qualified Dentist}

Qualified dentist is a proven corner-stone which arose the confidence in dental patients that their dental ailment will be remedied as at when due. Patients over time often encounter half-baked dental practitioners while searching for absolute cure to their dental ailment. Some dentists have little or no experience in rendering the anticipated services to the patients, in other to hasten the dental restoration process of the patients. Due to lack of qualified dentist referral services is often not the case as most dentist what to do it alone without wanting to involve others dentist competence for patients whose dental problem require special attention. Similarly, dentist with little qualification may inappropriately fix a tooth on patients or even proscribe wrong medicines for patients which may in the shortrun worse their dental condition.

\section{Inadequate Statistical Records}

In the less developed countries, dental restoration process has an administrative lags of inadequate statistical records about patient by most dentist. Less attention is often given to patients personal details in terms of recording patient's details appropriately for future reference. Additionally, test results of patients, drugs to be given to patients, consultation hours by patients and dentist recommendation are not recorded accurately. This scenario possesses constraint in the dental restoration process as experienced by patients.

\section{Lack of Adequate Dental Facilities}

Dental facilities are essential for effective and efficient performance of dentistry. In the less developed countries dental facilities are often lacking, this makes dental patients to seek foreign dental attention for their critical dental condition at the expense of their home countries dental treatment. Most dentist lack adequate facilities for high-quality oral health care [3]. Similarly, [3] added that infrastructure and other facilities are inadequate. Lack of adequate dental facilities hinders dentist operation on patient in the less developed countries hence slowing down the time frame for dental restoration of patients.

\section{Way-Forward}

In light of the challenges observed in the study, the following are some of the way-forward out of the challenges. 


\section{Good Communication}

Dentist should always ensure they check on their patients and ascertain their level of recovering. This will go a long way in cementing the communication lags experienced between the said parties. Additionally, this will assist in removing the challenge observed by [5] that it is rare today for dental practice to see the same patients for more than 20 years.

\section{On-the-Job Training}

On-the-job training will pave way for most dentist and their staffs to upgrade their skills, knowledge and competencies in the discharge of their professional duties.

\section{Proper Statistical Record Keeping}

Dentist and their assisting staffs should always endeavor to record patients prior information as at when due. This will help in check-mating the dental restoration process of the patients.

\section{Provision of Appropriate Dental Facilities}

Dentist should take proactive steps in working out modalities that will ensure that appropriate dental facilities are provided. This may involve private-public; public-public; or private-private collaboration.

Cost of dental services to patients should be reduced, in other for the patients to always see it deem fit to take dental treatment as at when need. This will helps to reduce the financial/economic burden to be borne by patients. This will go a long way in surmounting the later effect as opined by [6] that the increased burden of cost is a factor influencing a patient's health and may be linked to higher mortality.

\section{Conclusion}

Patients having dental ailment are predispose to undergo dental restoration. Dental restoration as observed from the study is a time frame process in which the patients tend to face some challenges that ranges from communication lags; cost of dental services; lack of qualified dentist; facilities; and inadequate statistical records. If the solution insights in terms of way- forwards and recommendations as proffer by the researcher are taking into consideration by dentist and other stakeholders in the health sectors in the less developed countries, it will help in removing these challenges faced by the patients.

\section{Recommendations}

Based on the finding of the study the following recommendations were made:

1. Government of the less developed countries should assist in funding of most dental institutions of learning and dental hospitals. This will pave way for acquisition of needed dental facilities and manpower development of dentist, which in the long-run helps nurturing and production of qualified dentist that would counter for patient's dental condition.

2. Collaboration (private-public; public-public; or private-private) should be encouraged among dentist. This will assist in raising condition of service among dentist and in the long-run for the betterment of patient's dental restoration process.

3. Workshops, symposia, seminars and field trips should be organized for dentist and their assisting staffs. This will help dentist to learn new skills and modus operandi in discharging their jobs.

\section{References}

1. Your Teeth and Cavities.

2. Wikipedia (2006) Dental Restoration.

3. Auluck (2005) Debate and Opinion: Oral Health of Poor People in Rural Areas of Developing Countries. JCDA 71(10).

4. Cambridge Dictionary.

5. Morin M (2014) Overcoming Four Main Dental Practice Challenges.

6. Schindler J (2016) Rising Oncology Medication Cost and the Impact on Patients.

7. (2016) Is there cure for high drug prices? A Special Investigation From Consumer Reports Best Buy Drugs. Consumer Reports 81(8): 52-60.

\section{Your next submission with Juniper Publishers will reach you the below assets}

- Quality Editorial service

- Swift Peer Review

- Reprints availability

- E-prints Service

- Manuscript Podcast for convenient understanding

- Global attainment for your research

- Manuscript accessibility in different formats ( Pdf, E-pub, Full Text, Audio)

- Unceasing customer service

Track the below URL for one-step submission https://juniperpublishers.com/online-submission.php 